\title{
Motivational training improves self-efficacy but not short-term adherence with asthma self- management: a randomized controlled trial
}

\author{
Claudia Steurer-Stey ${ }^{1}$, Maja Storch ${ }^{2}$, Susanne Benz ${ }^{2}$, Barbara Hobi $^{2}$, Barbara Steffen-Bürgi $^{3}$, \\ Johann Steurer ${ }^{4}$ and Milo A. Puhan ${ }^{4,5}$ \\ ${ }^{1}$ Department of General Practice and Health Services Research, University of Zurich, Zurich, Switzerland \\ ${ }^{2}$ ZRM Research, Unit of Continuing Education, Department of psychology, University of Zurich, Zurich, Switzerland \\ ${ }^{3}$ Centers for Development and Research in Nursing, Department of education and research, University Hospital of \\ Zurich, Zurich, Switzerland \\ ${ }^{4}$ Horten Centre for patient-oriented research and knowledge transfer, Department of Internal Medicine, University of \\ Zurich, Zurich, Switzerland \\ ${ }^{5}$ Department of Epidemiology, Johns Hopkins Bloomberg School of Public Health, Johns Hopkins University, \\ Baltimore, MD, USA
}

\begin{abstract}
Background: Adherence to self-management in asthma is poor. Aim: To investigate the effect of disease-unspecific motivational training on self-management adherence in addition to asthma-specific patient education. Methods: We randomized patients with partly controlled asthma to asthma education, with or without the Zurich Resource Model (ZRM) training. Main elements of the ZRM training are development of action-oriented personal goals and activation of resources to achieve and practice them in daily life. The primary outcome was adherence to self-monitoring and to a written personal action plan during three months. Secondary outcomes included patient-reported self-efficacy. Results: As control patients $(n=30)$ were younger, mostly male and had better asthma control compared with the intervention group $(n=30)$, we adjusted the analyses for these imbalances. Both groups showed excellent adherence to self-monitoring over three months [27 patients $(90.0 \%)$ in intervention and 25 patients (83.3\%) in control group, adjusted odds ratio: 1.28 $(0.24-6.78), P=0.78)]$. Patients in the ZRM group tended to adjust their medication more often [median 36\% days with action (IQR 11-62\%)] than control patients [9\% (0-43), $P=0.18$ ]. In both groups, actions were rarely in accordance with the action plan [median $20 \%$ of actions appropriate (IQR 0-37) in intervention and 11\% (IQR 0-56) in control group, $P=0.92$ ]. After three months, self-efficacy was significantly better with ZRM (adjusted difference on self-efficacy scale $2.31,95 \% \mathrm{Cl} 0.31-4.31, P=0.02$ ). Conclusion: Unspecific self-management training had no short-term effect on self-management adherence in asthma patients. Selfefficacy improved, but it is uncertain whether this translates into better long-term outcomes.
\end{abstract}

Key words: action plan; adherence; asthma; behaviour; self-management

Received 15 August 2013; revised 8 November 2013; accepted 10 November 2013;

first published online 30 January 2014

\section{Introduction}

Education in self-management is a cornerstone in asthma management (National Heart Lung and

Correspondence to: PD Dr med. Claudia Steurer-Stey, Department of General Practice and Health Services Research, University of Zurich, Pestalozzistrasse 24, CH-8091 Zurich, Switzerland. Email: claudia.stey@usz.ch
Blood Institute, 1991; The British Thoracic Society, 2003). Strong evidence exists that selfmanagement with an action plan reduces hospital admissions, emergency visits, and time off work or school (Gibson et al., 2003; Gibson and Powell, 2004).

Despite the evidence supporting asthma selfmanagement, adherence to self-monitoring and an

(C) Cambridge University Press 2014 
action plan in daily practice is low (Jones et al., 2000). Known explanations are that most asthma education programmes simply provide information without supporting the patients' inner motivation to be in control of their asthma or without explaining the benefits of self-monitoring and of an action plan. In addition, there is often insufficient coaching of patients in the proper use of an action plan so that they would feel more confident and safe in using it (Jones et al., 2000; Clark and Partridge, 2002; Partridge et al., 2006; Steurer-Stey et al., 2006). A further important reason for non-adherence to action plans is that relevant psychosocial and behavioural principles associated with improved adherence such as self-regulation and self-efficacy receive little consideration in daily practice (Bandura, 1977a; 1997; Clark et al., 2001). According to Bandura's social cognitive theory, an individual's perception of his or her ability to perform an action (self-efficacy) and his or her expectations that the behaviour will have desirable result are important mediators of performance (Bandura, 1977b; 1997; 2001). Evidence suggests that self-efficacy is a critical ingredient in the self-management process and for better health outcomes (Holman and Lorig, 1992; Lorig et al., 2001b; Barlow et al., 2002; Bodenheimer et al., 2002; Clark and Partridge, 2002; Calfee et al., 2006).

However, the extent to which patients acquire and apply self-management does not primarily depend on their knowledge of the disease but on a range of individual and non-disease-related factors, processes and resources. A key to successful patient self-management is to align their thoughts, feelings and behaviours with their treatment goals. We hypothesized that a wellestablished resource-activating training, which is not disease-specific, could improve the ability of asthma patients to adopt successful asthma self-management. We used the Zurich Resource Model (ZRM) training, which is based on cognitive-behavioural theory and supports people to define their intentions and actions to realize their goals in daily life (Storch and Krause, 2002; Storch, 2004) We studied in a randomized controlled trial whether the resource-activating ZRM training increases self-efficacy and improves asthma-specific self-management when added to a asthma-specific patient education programme in patients with partially controlled asthma.

\section{Methods}

\section{Study design and patient recruitment}

We conducted a randomized clinical trial comparing asthma-specific patient education with and without non-specific disease self-management training. We included patients who were 18 years and older with partially controlled asthma, according to Global Initiative for Asthma (GINA) guidelines (GINA, 2006) (symptoms during day, or night time, limitation in daily activities or sports because of asthma, need for rescue medication or unscheduled visits to the treating physician, emergency department visits because of exacerbations in the last six months). Asthma was defined by history, symptoms and criteria for reversibility with $\mathrm{FEV}_{1}$ increase of more than $12 \%$ and $200 \mathrm{ml}$ after bronchodilatation (GINA, 2006). We excluded patients with a psychiatric diagnosis such as major depression, schizophrenia, substance abuse or personality disorders, patients with other lung diseases, and patients with insufficient knowledge of the German language to follow the training and/or to complete questionnaires. Between October and December 2007, we identified potentially eligible patients from the outpatient clinic and emergency room of the University Hospital of Zurich and from referrals from general and chest physicians in the Canton of Zurich. Eligible patients willing to participate were informed about the study orally and in writing and asked for informed consent. We obtained approval from the local ethics committee and registered the trial in the International Standard Randomized Controlled Trial Number register (ISRCTN 33589847).

\section{Randomization and concealment of random allocation}

We used STATA software (STATA for Windows version 8.2, StataCorp, College Station, TX, USA) to generate the randomization list (ralloc command) with stratification for duration of illness (time since diagnosis $<5$ years or $\geqslant 5$ years) and age ( $<30$ years or $\geqslant 30$ years). The randomization list was kept concealed in an administrative office, otherwise not involved in the study and physicians and the course instructors used a central telephone service to obtain group allocation.

\section{Intervention for both groups}

All patients followed an asthma-specific education, which aimed to empower asthma patients to

Primary Health Care Research \& Development 2015; 16: 32-41 
better self-management. The programme consisted of group and individual education held by experienced asthma trainers (C.S., B.S.) at the Centre for Interdisciplinary Patient Education of the University Hospital of Zurich, Switzerland. The modules addressed three main dimensions: (1) Knowledge (pathophysiology of asthma, benefits and side effects of drugs), (2) Skills [inhalation technique, self-monitoring with peak expiratory flow (PEF) and symptom diaries], (3) Behaviour (interpretation of self-monitoring and appropriate action in case of asthma deterioration based on a written action plan that used a traffic light scheme to indicate a stable situation or worsening). The actions recommended to patients were:

- To continue with their usual daily asthma medication if PEF was $\geqslant 80 \%$ and they had no symptoms (green light).

- To double the dose of inhaled corticosteroids or combination therapy if PEF was $<80 \%$ and/or symptoms started to get worse over at least two days (yellow light).

- To start oral prednisone (50 mg daily over five to seven days) in addition to increased inhalation and contact their physician if PEF was $<50 \%$ and/or symptoms were shortness of breath during daily activities, awakenings during night, or rescue bronchodilator showed diminished response (orange-red light).

- To immediately contact a physician or call emergency if PEF was $<30 \%$ (dark red light).

\section{Disease non-specific self-management training for intervention group}

The intervention group participated in the Zurich Resource Model $\left(\mathrm{ZRM}^{\circledR}\right.$ ) training (www. zrm.ch) that is based on cognitive-behavioural theory. It focuses on self-aspects and aims to increase resources and self-efficacy in daily life. ZRM training also tries to enhance body awareness. Patients attended the two-day, group-based ZRM training and two refresher sessions of $2 \mathrm{~h}$ after 4 and 12 weeks. Two experienced ZRM trainers (S.B., B.H.) offered the training following the ZRM Training Manual (Storch and Krause, 2002). The heuristic model entailed and chosen in the Zurich Resource Model $\left(\mathrm{ZRM}^{\circledR}\right)$ training is the 'Rubicon' model. The model presents a sequence of individual steps leading towards systematic goal-realizing actions. The term 'Rubicon' is in reference to the decisive moment in $49 \mathrm{BC}$ when Julius Caesar, after much deliberation, decided to cross the river Rubicon with his soldiers, declaring 'alea jacta est' (The die is cast). The Rubicon model is, of course, not a theory to explain how wars are started, but it represents the basic problem in motivation psychology, namely, that there is a metaphorical Rubicon to cross between an intention to act and the action.

The ZRM training consists of five phases that extend over the main and refresher sessions.

(1) Activation of personal resources. A set of pictures eliciting positive feelings is shown to patients followed by a question about which pictures evoke positive somatic responses such as pleasant body feeling.

(2) Goal setting. Action-oriented personal goals are discussed in small groups and written down together with potential means to achieve them and potential barriers.

(3) Identification of individual resources. Individual resources to achieve personal goals are identified, which is enhanced by embodiment techniques with posture, gesture and facial expressions. Embodiment acknowledges that the mind is embedded in the body and empirical evidence shows multiple ways in which the body influences mental processes, emotion and behaviour. Participants develop their individual goal-related embodiment, which subjectively expresses the emotion and behaviours that facilitates goal reaching.

(4) Action. The goal-oriented use of identified resources in different situations is practiced in role plays. A particular emphasis is put on the identification of 'warning signals' for unwanted emotions or behaviours and on strategies to stop them by positive self-instructions and thought-stop techniques.

(5) Transfer into daily life. The results of the ZRM training are revised and discussed with the aim to integrate changes into daily life.

A detailed description of the training methods and procedures is available on request from the authors and has been published elsewhere (Storch and Krause, 2002, Storch, 2004).

\section{Outcome measures}

Our primary outcome measures were adherence to self-monitoring and adherence to the individualized 
action plan over the first three months. We defined, a priori, adherence to self-monitoring as measurement and recording of PEF and symptoms on at least four of seven days on average over the study period. Thus, for three months (90 days), we defined patients to be adherent to self-monitoring if they registered their symptoms and/or peak-flow at least once per day on 51 of the 90 days. Patients were instructed to monitor PEF and symptoms daily and to complete the asthma diary. For PEF monitoring, we instructed participants how to use the microlife ${ }^{\circledR}$ asthma monitor device (Micro Direct Inc. 803, Lewiston, ME, USA, www.microdirect.com). The microlife ${ }^{\circledR}$ has a memory that stores up to 240 peak flow measurements that allowed us, as a measure of compliance, to check whether patients completed the diary correctly. For symptom monitoring, we instructed patients how to rate the symptom scores in the asthma diary for dyspnoea, cough and sputum production on a scale from 0 no symptoms, 1 mild symptoms, 2 moderate symptoms and 3 severe symptoms.

We defined adherence to the action plan if $80 \%$ of actions taken by patients to adjust their medication were correct according to the action plan. A correct action was defined as the action that was specified in the action plan for the respective description of the traffic light scheme (see above). Incorrect actions included adjustments to medication when it was not needed (green light), no adjustments to medication when it was recommended (yellow, orange and red zone) and no immediate contact to a health-care professional in the case of emergency (red zone). When patients adjusted their medication, although there was no need to (green light), we considered it a noncorrect action. Patients recorded every day on their asthma diary whether and how they adjusted their medication. As this outcome depended on adherence to self-monitoring, we only assessed this outcome for patients with adherence to selfmonitoring as defined above.

\section{Patient-reported self-efficacy}

We used the validated German version of the widely used general perceived self-efficacy scale that measures an individual's perception of his or her ability to perform an action (Schwarzer and Born, 1977; Schwarzer, 1992) The scale includes 10 items that are answered on a four-point Likerttype scale.

\section{Patient-reported self-regulation}

We used the validated Volitional Components Inventory (Kuhl and Fuhrmann, 1998). Specific issues addressed include the development of selfcontrol and self-regulation. We focused on domains of the Volitional Components Inventory that we deemed most relevant for the scope of our trial: The attention control domain that captures to what extent personal goals meet personal needs, the selfmotivation domain, the intention control domain that measures the capability of being action oriented, and the impulse control domain that captures how the expectations of other people meet a person's own goal and intentions.

\section{Sample size}

We based our sample size on the primary outcome 'adherence to the action plan' at three months. According to published data (Adams et al., 2001; Toelle and Ram, 2004), we expected that $30 \%$ of control group patients would adhere to the action plan as defined above. For patients in the intervention group we expected an adherence of $75 \%$. To detect the difference of $45 \%$ between the groups, we needed a total sample size (both groups) of 46 patients at a significance level of 0.05 (two-sided) and a power of $80 \%$. Assuming that $15 \%$ of the patients would not adhere to selfmotoring and are thus not eligible for the analysis and assuming a dropout rate of $10 \%$ during the first three months, the required sample size increased to 60 patients.

\section{Statistical analysis}

We included all patients in the analysis according to their randomization (intention-to-treat) if they started the unspecific asthma patient education. We used medians [interquartile ranges (IQR)] to describe non-normally distributed data and means [standard deviation (SD)] for normally distributed data. We used the non-parametric Wilcoxon rank-sum test to compare adherence with self-monitoring and with the action plan and logistic regression analysis with adjustment for baseline imbalances to compare the odds for adherence with self-monitoring as defined above. To compare groups for secondary outcomes, we used linear regression analysis, again with the adjustment for baseline imbalances. We performed all analyses using STATA for Windows 10.1 (Stata Corporation).

Primary Health Care Research \& Development 2015; 16: 32-41 


\section{Results}

\section{Patients}

We assessed 72 patients for eligibility between October and December 2008. Five patients did not meet the inclusion criteria and six refused to participate. We randomized 61 patients to the intervention $(n=30)$ and control group $(n=31)$, respectively. One patient in the control group discontinued owing to relocation shortly after randomization and did not start the education at all. As we did not want to impute all follow-up data for this single patient, we analysed the data of 60 patients (Figure 1). Despite stratified randomization, control patients were younger, mostly male and reported better asthma control compared with the intervention group (Table 1). We therefore adjusted the analyses for these imbalances.

\section{Adherence to self-monitoring}

Table 2 shows that patients of both groups recorded their PEF and symptom monitoring on most days. Both groups showed high adherence to self-monitoring over three months [27 patients $(90.0 \%)$ in intervention and 25 patients $(83.3 \%)$ in control group, $P=0.65]$. Patients with the intervention did not show significantly better adherence to self-monitoring [unadjusted odds ratio 1.80 (95\% CI $0.39-8.32, P=0.45)$, and adjusted odds ratio $1.28(0.24-6.78), P=0.78]$.

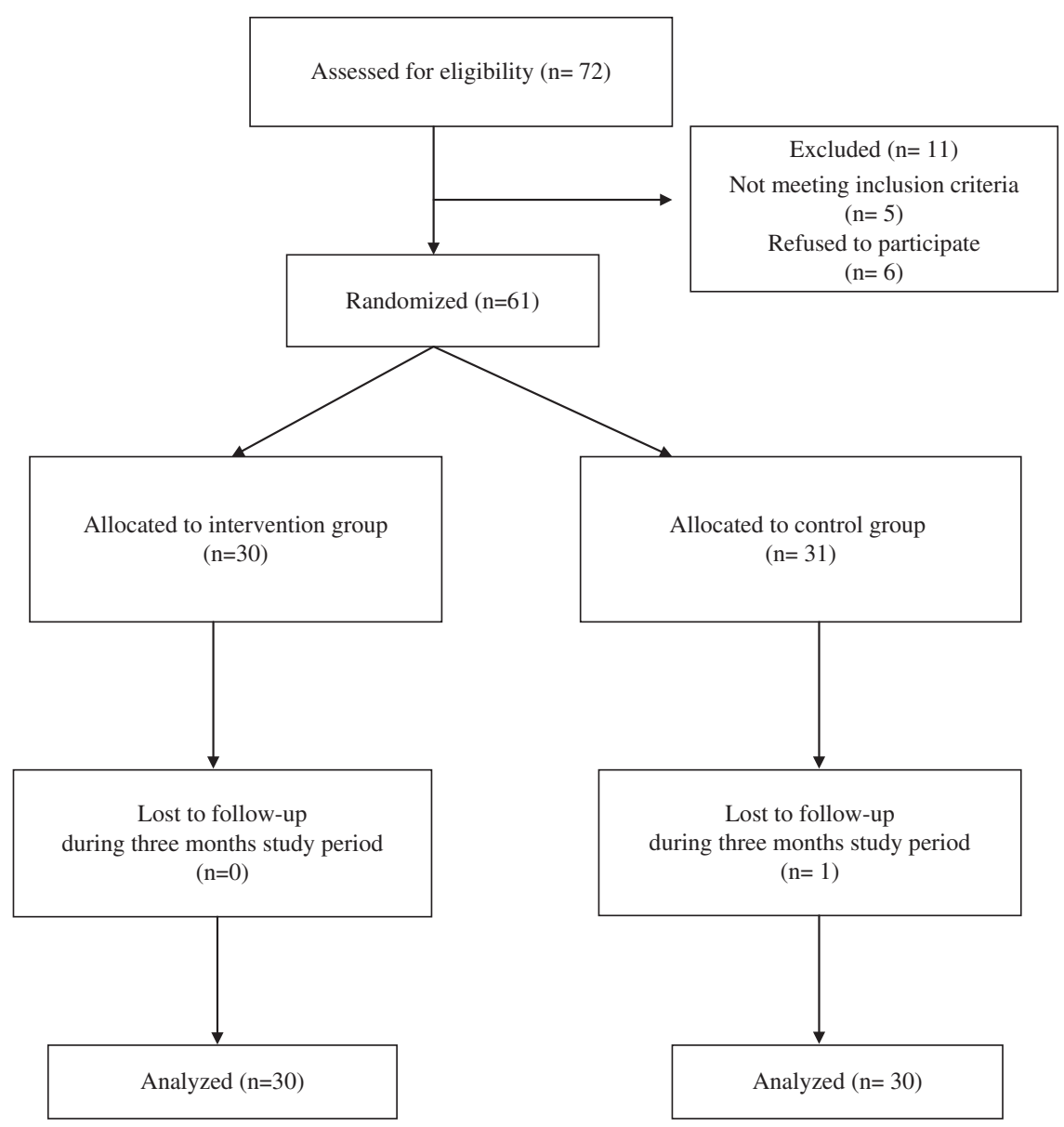

Figure 1 Flow diagram

Primary Health Care Research \& Development 2015; 16: 32-41 
Table 1 Baseline characteristics

\begin{tabular}{|c|c|c|}
\hline Asthma therapy before randomization & \multicolumn{2}{|c|}{$n=61$} \\
\hline $\begin{array}{l}\text { None or SABA on demand only } \\
\text { ICS plus LABA/SABA } \\
\text { LTRA } \\
\text { LABA without ICS }\end{array}$ & \multicolumn{2}{|c|}{$\begin{array}{l}13(21.3 \%) \\
41(67 \%) \\
3(4.9 \%) \\
3(4.9 \%)\end{array}$} \\
\hline Patients with peak flow measuring before randomization & \multicolumn{2}{|c|}{$29(47.5 \%)$} \\
\hline Randomization & $\begin{array}{l}\text { Patient education } \\
\quad(n=31)\end{array}$ & $\begin{array}{l}\text { Patient education + ZRM } \\
(n=30)\end{array}$ \\
\hline $\begin{array}{l}\text { Age (SD) } \\
\text { Gender [male/female (\%)] } \\
\text { Years since diagnosis [years (SD)] } \\
\text { Peak flow baseline [L/min (SD)] } \\
\text { Patients with }\end{array}$ & $\begin{array}{c}33.7(10.0) \\
14 / 17(45 / 55) \\
15.1(9.5) \\
504(117)\end{array}$ & $\begin{array}{c}43.2(14.9) \\
11 / 19(37 / 63) \\
17.7(14.9) \\
444(133)\end{array}$ \\
\hline $\begin{array}{l}>2 \text {-day symptoms/week (\%) } \\
>2 \text {-night symptoms/month (\%) } \\
\text { Limitation in daily activities (\%) } \\
\text { Use of rescue medication (\%) in last month }\end{array}$ & $\begin{array}{r}13(43.3) \\
6(20.0) \\
12(40.0) \\
6(20.0)\end{array}$ & $\begin{array}{r}14(48.3) \\
9(31.0) \\
14(48.3) \\
14(48.3)\end{array}$ \\
\hline $\begin{array}{l}\text { Self-efficacy } \\
\text { Self-regulation }\end{array}$ & $29.8(4.7)$ & $28.7(4.2)$ \\
\hline $\begin{array}{l}\text { Attention control } \\
\text { Self motivation }^{\mathrm{a}} \\
\text { Intention control }^{\mathrm{c}} \\
\text { Impulse control }^{\mathrm{d}}\end{array}$ & $\begin{array}{l}10.6(2.3) \\
10.1(2.6) \\
11.1(2.5) \\
12.1(3.1)\end{array}$ & $\begin{array}{l}10.3(2.7) \\
10.0(2.8) \\
10.4(2.7) \\
10.8(3.7)\end{array}$ \\
\hline
\end{tabular}

SABA = short acting betaagonist; ICS = inhaled corticosteroids; LABA = long acting betaagonsist; LRTA = leucotriene receptor antagonist; $Z R M=$ Zurich Resource Model.

${ }^{a}$ Scale 1 of Volitional Components Inventory.

${ }^{\mathrm{b}}$ Scale 2 of Volitional Components Inventory.

${ }^{c}$ Scale 7 of Volitional Components Inventory.

${ }^{\mathrm{d}}$ Scale 10 of Volitional Components Inventory.

\section{Adherence to action plan}

Very few patients required an adjustment of their medication according to their PEF and symptom recordings as expressed by the average number of days requiring action (Table 2). Patients with the ZRM training adjusted their medication more frequently than patients in the control group, but the difference was not statistically significant $(P=0.20)$. The average number of days with adjustment of medication was substantially higher than the average number of days where an adjustment was necessary. As a consequence, only few patients made adjustments to their medication according to their action plan either because they did not act when recommended, or more frequently, because they made adjustments, although this was not indicated. On average, a median of $11 \%$ (IQR $0-56$ ) of actions taken by control group patients were correct compared with $20 \%$ (IQR $0-37$ ) of actions in the intervention group $(P$-value for difference $=0.92)$.
Because the number of days with action required by the action plan was low, and consequently a proportion of correct actions could not be calculated in any sensible way, we could not compare the proportion of patients with adherence to the action plan ( $80 \%$ of actions taken by patients to adjust their medication were correct).

\section{Patient-reported self-efficacy}

Patients with the disease unspecific behavioural training showed significantly improved selfefficacy after three months compared with control group patients. The adjusted difference (linear regression analysis) between groups was 2.31 (95\% CI 0.31-4.31) points in the general perceived self-efficacy scale, $P=0.024$ (Table 3 ).

\section{Patient-reported self-regulation}

Both groups showed improvements in selfregulation after three months. Improvements 
Table 2 Adherence to self-monitoring and to action plan during the first three months

\begin{tabular}{|c|c|c|c|}
\hline & $\begin{array}{l}\text { Patient } \\
\text { education plus } \\
\text { ZRM }(n=30)\end{array}$ & $\begin{array}{l}\text { Patient } \\
\text { education alone } \\
\text { (control) }(n=30)\end{array}$ & $P$ value ${ }^{\text {a }}$ \\
\hline \multicolumn{4}{|l|}{ Adherence to self-monitoring } \\
\hline $\begin{array}{l}\text { Percentage of days with peak flow measurements } \\
\text { [median (IQR) }]^{\mathrm{b}}\end{array}$ & $91(78-97)$ & $82(70-93)$ & 0.13 \\
\hline $\begin{array}{l}\text { Percentage of days with symptom recordings } \\
\text { [median (IQR) }]^{\mathrm{c}}\end{array}$ & $99(42-100)$ & $93(41-99)$ & 0.38 \\
\hline Patients (\%) with adherence to self-measurement ${ }^{d}$ & $27(90.0)$ & $25(83.3)$ & 0.65 \\
\hline \multicolumn{4}{|l|}{ Adherence to action plan } \\
\hline $\begin{array}{l}\text { Number of days with action required by peak flow } \\
\text { monitoring [median (IQR)] }\end{array}$ & $7(0-44)$ & $1(0-12)$ & 0.39 \\
\hline $\begin{array}{l}\text { Number of days with action required by symptom } \\
\text { monitoring [median (IQR)] }\end{array}$ & $8(2-17)$ & $3(0-9)$ & 0.17 \\
\hline Number of days with action [median (IQR)] & $32(10-55)$ & $8(0-31)$ & 0.20 \\
\hline $\begin{array}{l}\text { Percentage of correct actions among all actions } \\
\text { [median (IQR)] }\end{array}$ & $20(0-37)$ & $11(0-56)$ & 0.92 \\
\hline Patients with asthma control therapy & $90 \%$ & $93 \%$ & 0.68 \\
\hline
\end{tabular}

were larger but not statistically significant in patients with the ZRM training (Table 3).

\section{Discussion}

\section{Main results}

The primary finding of this randomized controlled study is that the disease non-specific selfmanagement training did not increase adherence to asthma self-management with an action plan. This may be because the intervention was not effective, but it is more likely because of the fact that participants in both groups experienced very few days that warranted adjustment of treatment. With much lower than expected event rates, capturing a difference in groups became unlikely. However, we observed a significant increase in self-efficacy, which is a critical feature of behaviour change processes in chronic diseases (Lorig and Holman, 2003).

\section{Adherence to self-management}

In asthma, to do the right thing at the right time reduces morbidity and even mortality (Gibson et al., 2003; Partridge et al., 2006). However, data show that patients wait too long and do not react adequately with deterioration (Partridge et al., 1997; Steurer-Stey et al., 2005). Patients in both groups showed better adherence to selfmonitoring with PEF and symptoms than usually reported (Verschelden et al., 1996). One potential reason is that a team trained and experienced in evidence-based asthma education educated all patients. It is likely that this education improved patients' inner motivation to be in control in both groups and prompted patients to better adherence, making the detection of an additional effect difficult.

Patients in both groups experienced few days of worsening that warranted an adjustment of treatment. Several reasons may explain this. It is possible that our tools used for self-assessment (peak flow and symptom logs) underestimated symptoms so that treatment was not adjusted, although it may have been necessary in some situations. Perhaps, more pertinently, the asthma education included an optimization of asthma treatment according to guidelines. This not only could have prompted patients to better adherence, but substantially also affect asthma control and hence reduced the number of occasions on which adjustment of 
Table 3 Patient-reported self-efficacy and self-regulation

\begin{tabular}{|c|c|c|c|c|}
\hline & \multicolumn{2}{|c|}{$\begin{array}{l}\text { Change from baseline to } \\
\text { follow-up }\end{array}$} & \multirow[t]{2}{*}{$\begin{array}{l}\text { Difference between } \\
\text { groups }\end{array}$} & \multirow[t]{2}{*}{$\begin{array}{l}\text { Adjusted difference } \\
\text { between groups }^{a}\end{array}$} \\
\hline & $\begin{array}{l}\text { Patient } \\
\text { education }\end{array}$ & $\begin{array}{l}\text { Patient } \\
\text { education + ZRM }\end{array}$ & & \\
\hline $\begin{array}{l}\text { Self-efficacy scale scoresafter } \\
\text { three months }\end{array}$ & $0.93(3.36)$ & $3.50(4.08)$ & $2.57(0.62-4.52), P=0.011$ & $2.31(0.31-4.31), P=0.024$ \\
\hline \multicolumn{5}{|l|}{$\begin{array}{l}\text { Self-regulation scores after } \\
\text { three months }\end{array}$} \\
\hline Attention control $^{\mathrm{b}}$ & $0.93(2.12)$ & $1.50(2.94)$ & $0.57(-0.77-1.91), P=0.40$ & $0.30(-0.91-1.51), P=0.62$ \\
\hline Self motivation ${ }^{c}$ & $0.48(2.03)$ & $0.87(2.71)$ & $0.39(-0.86-1.63), P=0.54$ & $0.08(-1.10-1.26), P=0.89$ \\
\hline Intention control ${ }^{\mathrm{d}}$ & $0.34(2.50)$ & $1.73(2.48)$ & $1.39(0.09-2.69), P=0.04$ & $0.95(-0.36-2.25), P=0.15$ \\
\hline Impulse control $^{\mathrm{e}}$ & $1.72(2.30)$ & $1.60(3.84)$ & $-0.12(-1.78-1.53), P=0.88$ & $-0.76(-2.31-0.78), P=0.33$ \\
\hline
\end{tabular}

ZRM = Zurich Resource Model.

${ }^{2}$ Adjusted for age, gender and baseline peak expiratory flow (PEF).

${ }^{\mathrm{b}}$ Scale 1 of Volitional Components Inventory.

${ }^{\mathrm{c}}$ Scale 2 of Volitional Components Inventory.

${ }^{\mathrm{d}}$ Scale 7 of Volitional Components Inventory.

${ }^{\mathrm{e}}$ Scale 10 of Volitional Components Inventory.

treatment was indicated. Low rates of adjustment of medications as recommended by the action plan have been reported earlier (Adams et al., 2001) and this is still not fully understood. An explanation is that patients modify their interpretation of the action plan on the basis of personal experiences and perceptions of asthma (Toelle and Ram, 2004). To gain more insights into these processes and to understand what influences the patients' attitude towards self-initiated treatment changes, it may be necessary to complement trial evidence with qualitative research (Douglass et al., 2002).

\section{Self-efficacy and self-regulation}

Self-regulation broadly denotes the processes through which people bring their thoughts, feelings, and behaviour in line with goals (Kuhl and Fuhrmann, 1998; Clark et al., 2001). Self-efficacy, an individual's perception of his or her ability to perform an action and in health terms a patient's belief regarding the ability for certain health behaviours, is a critical ingredient in the selfmanagement process (Bandura, 1977b; 1997; 2001; Holman and Lorig, 1992; Lorig et al., 2001a; Barlow et al., 2002; Lorig and Holman, 2003; Creer, 2008).

The task entailed in the ZRM training is to identify and to understand how new desirable behaviour can be successfully implemented in a person's daily life. It analyses the basic problem in motivation psychology, namely, that there is a metaphorical Rubicon to cross between an intention to act and the action. In clinical work, we often realize that the extent to which patients acquire and apply self-management depends not mainly on their knowledge and information about the disease but on disease-unspecific factors and their general ability to transform an intention to act into the action, the crossing of the 'Rubicon'. Despite significantly improved self-efficacy and self-regulation, patients with the ZRM training did not show better adherence to the action plan after three months. The higher self-efficacy and selfregulation may be due to an initial rise in selfefficacy that is not maintained and does not translate into better adherence to the action plan. It may also reflect that patients start thinking, as a consequence of the ZRM training, about what they want to do but have not yet succeeded to do so. Behavioural changes in chronic conditions may need time to translate into health benefits, and therefore our study period was likely to be too short. Another explanation for the gap between improved self-efficacy and unimproved adherence may be that adherence to self-management takes into account different selfaspects, and therefore non-adherence, an irrational act from the doctor's view, may be a rational action from a patient's perspective (Creer, 2008). We may have to refocus our perspective more towards an understanding of how patients take decisions in the self-management process.

Primary Health Care Research \& Development 2015; 16: 32-41 


\section{Strength and limitations of our study}

A strength of this study is our adherence to methodological standards for randomized trials and an explicit definition of our interventions. A limitation is the good asthma control during the study period as a consequence of our intensive control intervention that clearly exceeded usual asthma care. The power calculation was based on detecting a large effect as a consequence; the sample size was too small to detect small changes. In addition, selfreported symptoms may have contributed to smaller between-group differences as non-differential measurement error attenuates effect estimates towards the null. Finally, we could not determine whether self-monitoring or adherence changed from before randomization to any time point during follow-up because we did not have a run-in period before randomization and because we did not want to rely on self-reported data based on the recall of patients.

\section{Conclusion}

Unspecific self-management training did not increase asthma self-management adherence in short term. Further research should try to open the 'black box' of patient self-management by studying the processes of self-management from the patients' perspective.

\section{Acknowledgements}

The authors thank Mrs B. Bichsel von Arb for the study coordination. They also thank Mrs K. Studer for data collection.

\section{Conflicts of Interest}

Claudia Steurer-Stey gives lectures for AstraZeneca, Glaxo Wellcome and Merck Scharp \& Dome, Boehringer Ingelheim, Pfizer and Novartis. The second author is employed by Sandwell and West Birmingham CCG. Milo Puhan, Johann Steurer, Barbara Steffen-Bürgi, Susanne Benz, Barbara Hobi: none. Maja Storch together with Frank Krause developed the Zurich Resource Model. She is director of the ZRM research unit at the University of Zurich.

\section{Authors' contribution}

All authors made a substantial contribution to this manuscript, that is, conception, design and drafting. Primary Health Care Research \& Development 2015; 16: 32-41

\section{Funding}

The study was supported by an unrestricted grant from AstraZeneca Switzerland for research in patient education and asthma. K. Studer received salary support from the grant.

\section{References}

Adams, R.J., Smith, B.J. and Ruffin, R.E. 2001: Patient preferences for autonomy in decision making in asthma management. Thorax 56, 126-32.

Bandura, A. 1977a: Self-efficacy: toward a unifying theory of behavioral change. Psychological Review 84, 191-215.

Bandura, A. and Adams, N.E. 1977b: Analysis of self-efficacy theory of behavioral change. Cognitive Therapy and Research 1, 287-304.

Bandura, A. 1997: Self-efficacy the exercise of control. New York, NY: W H Freeman/Times Books/Henry Holt $\& \mathrm{Co}$

Bandura, A. 2001: Social cognitive theory: an agentic perspective. Annual Review of Psychology 52, 1-26.

Barlow, J., Wright, C., Sheasby, J., Turner, A. and Hainsworth, J. 2002: Self-management approaches for people with chronic conditions: a review. Patient Education and Counseling 48, 177-87.

Bodenheimer, T., Lorig, K., Holman, H. and Grumbach, K. 2002: Patient self-management of chronic disease in primary care. Journal of the American Medical Association 288, 2469-75.

The British Thoracic Society. 2003: British guideline on the management of asthma. Thorax 58(Suppl. 1), i1-94.

Calfee, C.S., Katz, P.P., Yelin, E.H., Iribarren, C. and Eisner, M.D. 2006: The influence of perceived control of asthma on health outcomes. Chest 130, 1312-18.

Clark, N.M., Gong, M. and Kaciroti, N. 2001: A model of selfregulation for control of chronic disease. Health Education \& Behavior 28, 769-82.

Clark, N.M. and Partridge, M.R. 2002: Strengthening asthma education to enhance disease control. Chest 121, 1661-69.

Creer, T.L. 2008: Behavioral and cognitive processes in the selfmanagement of asthma. Journal of Asthma 45, 81-94.

Douglass, J., Aroni, R., Goeman, D., Stewart, K., Sawyer, S., Thien, F. and Abramson, M. 2002: A qualitative study of action plans for asthma. British Medical Journal 324, 1003-1005.

Gibson, P.G. and Powell, H. 2004: Written action plans for asthma: an evidence-based review of the key components. Thorax 59, 94-99.

Gibson, P.G., Powell, H., Coughlan, J., Wilson, A.J., Abramson, M., Haywood, P., Bauman, A., Hensley, M.J. and Walters, E.H. 2003: Self-management education and regular practitioner review for adults with asthma. Cochrane Database of Systematic Reviews, CD001117. 
Global Initiative for Asthma (GINA). 2006: From the Global Strategy for Asthma Management and Prevention. Available at: http://www.ginasthma.org/

Holman, H. and Lorig, K. 1992: Perceived self-efficacy in selfmnagement of chronic disease. In Schwarzer, R., editors, Self-efficacy: thought control of action, pp. 305-323. Washington, DC: Hemisphere Publishing Corp.

Jones, A., Pill, R. and Adams, S. 2000: Qualitative study of views of health professionals and patients on guided self management plans for asthma. British Medical Journal 321, 1507-10.

Kuhl, J. and Fuhrmann, A. 1998: Decomposing self-regulation and self-control: the volitional components inventory. In Heckhausen, J., Dweck, C.S. editors, Motivation and selfregulation across the life span, pp. 15-49. New York, NY, US: Cambridge University Press.

Lorig, K.R. and Holman, H. 2003: Self-management education: history, definition, outcomes, and mechanisms. Annals of Behavioral Medicine 26, 1-7.

Lorig, K.R., Ritter, P., Stewart, A.L., Sobel, D.S., Brown, B.W. Jr, Bandura, A., Gonzalez, V.M., Laurent, D.D. and Holman, H.R. 2001a: Chronic disease self-management program: 2-year health status and health care utilization outcomes. Medical Care 39, 1217-23.

Lorig, K.R., Sobel, D.S., Ritter, P.L., Laurent, D. and Hobbs, M. 2001b: Effect of a self-management program on patients with chronic disease. Effective Clinical Practice 4, 256-62.

National Heart Lung and Blood Institute. 1991: Expert Panel Report 1: Guidelines for the diagnosis and management of asthma. U.S. Department of Health and Human Services, National Institutes of Health. Available at: http://www.nhlbi. nih.gov/guidelines/index.htm

Partridge, M.R., Latouche, D., Trako, E. and Thurston, J.G. 1997: A national census of those attending UK accident and emergency departments with asthma. The UK National
Asthma Task Force. Journal of Accident \& Emergency Medicine 14, 16-20.

Partridge, M.R., Van Der Molen, T., Myrseth, S.E. and Busse, W.W. 2006: Attitudes and actions of asthma patients on regular maintenance therapy: the INSPIRE study. BMC Pulmonary Medicine 6, 13.

Schwarzer, R. editors. 1992: Self-efficacy: thought control of action. Washington, DC: Hemisphere.

Schwarzer, R. and Born, A. 1977: Assessment of general perceived self-efficacy in thirteen cultures. World Pschology 3, 177-90.

Steurer-Stey, C., Fletcher, M., Vetter, W. and Steurer, J. 2006: Patient education in asthma: a survey of physicians' knowledge of the principles and implementation of self management in practice. Swiss Medical Weekly 136, 561-65.

Steurer-Stey, C., Grob, U., Jung, S., Vetter, W. and Steurer, J. 2005: Education and a standardized management protocol improve the assessment and management of asthma in the emergency department. Swiss Medical Weekly 135, 222-27.

Storch, M. 2004: Resource-activating selfmanagement with the Zurich Resource Model (ZRM). European Psychotherapy 5, 27-64.

Storch, M. and Krause, F. 2002: Selbstmanagement - ressourcenorientiert. Grundlagen und Trainingsmanual für die Arbeit mit dem Zürcher Ressourcen Modell (Self management-ressource oriented theoretical background an training manual of the Zurich Resource Model $\left(Z R M^{\circledR}\right)$. Aufl. Huber: Bern.

Toelle, B.G. and Ram, F.S. 2004: Written individualised management plans for asthma in children and adults. Cochrane Database of Systematic Reviews 1, 1-22.

Verschelden, P., Cartier, A., L'archeveque, J., Trudeau, C. and Malo, J.L. 1996: Compliance with and accuracy of daily selfassessment of peak expiratory flows (PEF) in asthmatic subjects over a three month period. European Respiratory Journal 9, 880-85. 